\title{
A prospective, randomised, placebo-controlled study to identify biomarkers associated with active treatment in psoriatic arthritis: effects of adalimumab treatment on synovial tissue
}

\author{
A W R van Kuijk ${ }^{1}$ D M Gerlag, ${ }^{1} \mathrm{~K}$ Vos, ${ }^{1,2} \mathrm{G}$ Wolbink, ${ }^{2} \mathrm{M}$ de Groot ${ }^{3} \mathrm{M} \mathrm{A}$ de $\mathrm{Rie}^{3}$ \\ A H Zwinderman, ${ }^{4}$ B A C Dijkkmans, ${ }^{2,5}$ P P Tak'
}

${ }^{1}$ Division of Clinical Immunology and Rheumatology, Academic Medical Center/University of Amsterdam, Amsterdam, The Netherlands; ${ }^{2}$ Jan van Breemen Institute, Amsterdam, The Netherlands; ${ }^{3}$ Department of Dermatology, Academic Medical Center/University of Amsterdam, Amsterdam, The Netherlands;

${ }^{4}$ Department of Clinical Epidemiology and Biostatistics, Academic Medical Center/ University of Amsterdam, Amsterdam, The Netherlands; ${ }^{5}$ Department of Rheumatology, VU Medical Center, Amsterdam, The Netherlands

\section{Correspondence to:}

P P Tak, Division of Clinical Immunology and Rheumatology, F4-105, Academic Medical Center/University of Amsterdam, PO Box 22700, 1100 DE Amsterdam, The Netherlands; P.P.Tak@amc.uva.n

Accepted 13 July 2008 Published Online First 22 July 2008

\section{ABSTRACT}

Objective: To determine which of the changes in synovial tissue correlates best with clinical response associated with effective therapy (adalimumab) to facilitate the planning of future studies with therapeutic agents for psoriatic arthritis (PsA).

Methods: A total of 24 patients with active PsA were randomised to receive adalimumab $(n=12)$ or placebo $(n=12)$ for 4 weeks. Synovial biopsies were obtained before and after 4 weeks of treatment.

Immunohistochemical analysis was performed to characterise the cell infiltrate, expression of cytokines and matrix metalloproteinases (MMPs) and vascularity. Sections were analysed by digital image analysis. Statistical analysis was performed using covariance analysis.

Results: The mean Disease Activity Score in 28 joints (DAS28) after 4 weeks was 1.92 units lower $195 \%$ confidence interval (CI) 1.07 to 2.77) after adalimumab therapy compared with placebo. Paired pretreatment and post-treatment synovial samples were available from 19 patients. Many cell types were reduced after adalimumab treatment compared to placebo. After applying a ranked analysis of covariance (ANCOVA) model to correct for baseline imbalances, a significant effect of treatment was observed on CD3-positive cells: there was a median reduction of 248 cells $/ \mathrm{mm}^{2}$ after adalimumab versus placebo treatment $(p=0.035)$. In addition, the expression of MMP13 was significantly reduced after active treatment: the integrated optical density (IOD) $/ \mathrm{mm}^{2}$ was 18190 lower after adalimumab treatment as compared to placebo ( $p=0.033)$.

Conclusion: Adalimumab therapy in PsA is associated with a marked reduction in T cell infiltration and MMP13 expression in synovial tissue, suggesting that these parameters could be used as biomarkers that are sensitive to change after active treatment in small proof of concept studies in PsA.

Because the synovium is a primary site of inflammation, there is increasing interest in studying the synovial tissue (ST) of patients with rheumatoid arthritis (RA) and psoriatic arthritis (PsA). In addition to the use of synovial biopsies for diagnostic purposes ${ }^{12}$ and pathogenetic studies, ${ }^{34}$ serial synovial biopsies have been used to evaluate the effects of novel treatments. ${ }^{5}{ }^{6}$ This approach has been proposed to screen for therapeutic effects of novel antirheumatic interventions. ${ }^{7}$
The increase in the development of a variety of new, targeted therapies clearly raises the need for sensitive biomarkers, which could be used for selection purposes during the development process. In RA a decrease in synovial macrophages has been shown to correlate with clinical improvement. ${ }^{8-10}$ No synovial changes were detectable with analysis of serial synovial samples from patients with RA who received either placebo or ineffective treatment. ${ }^{91-13}$ This suggests that analysis of serial biopsies could be used as a screening method to test new compounds requiring relatively small numbers of subjects. The absence of changes in the ST after treatment would suggest that the therapy is probably not effective.

To date, only a few studies have been conducted in PsA evaluating synovial changes after therapy. These studies were not placebo controlled, with biopsies taken at different time points and in part with variable results. ${ }^{6}{ }^{14-18}$ Based on the limited data available it was hypothesised that an early decrease in macrophages (or macrophage subsets), combined with decrease in vascular markers and/or adhesion molecules, which were observed in some of these studies, would best predict clinical response in PsA.

The primary objective of this study was, therefore, to investigate the early changes in the ST alongside clinical response, by using a known clinically effective therapy (ie, adalimumab $40 \mathrm{mg}$ subcutaneously every other week), ${ }^{19}$ to identify sensitive biomarkers that may facilitate the planning of future studies with novel agents to treat PsA.

\section{PATIENTS AND METHODS \\ Patients}

Patients with PsA fulfilling the ClASsification of Psoriatic ARthritis (CASPAR) criteria for PsA, ${ }^{20} 21$ aged 18-80 years, were included into the study after written informed consent was obtained. Patients had to have active disease at time of enrolment, defined by the presence of at least 2 tender and 2 swollen joints out of the 68 joints for tenderness and 66 joints for swelling assessed. One of the swollen joints had to be a knee, ankle or wrist joint that was accessible for arthroscopy. Patients were allowed to use concomitant methotrexate, which had to be stable for at least 28 days. They were not allowed to use any other diseasemodifying antirheumatic drugs (DMARDs)
This paper is freely avalabl online under the BMJ Journa unlocked scheme, see http $/ /$ ard.bmi.com/info/unlocked.dtl 
1 month prior to baseline. For leflunomide, a 2-month washout period was required. Use of non-steroidal anti-inflammatory drugs was allowed, provided that the dose had been stable for at least 28 days. Parenteral, intra-articular or oral use of corticosteroids within 28 days before enrolment into the study was not allowed. Topical treatments for psoriasis were not allowed 14 days prior to baseline, with the exception of low potency (class I) topical steroids to be used on scalp, palms, groin and/or soles of feet only. Other exclusion criteria were the use of any biological agent or investigational drug within the previous 6 months and having a history of tuberculosis or a malignancy in the past 10 years. Infection with HIV, hepatitis B or C virus was excluded via serological testing. Patients with another serious infection within 4 weeks before baseline, or a significant history of cardiac, renal, neurological or metabolic disease were excluded from the study. Female patients who were pregnant or breastfeeding were not allowed to enter the study.

\section{Study protocol}

This was a randomised, double-blind, placebo-controlled, single centre study performed at the Academic Medical Center of the University of Amsterdam. The study protocol was approved by the Medical Ethics Committee of the institute and all patients signed informed consent before the start of the study. They had a complete medical history taken and underwent a full physical examination, including joint assessment by a rheumatologist and skin assessment by a dermatologist. Routine clinical chemistry, haematology and urinalysis assessments were performed, as well as a chest $x$ ray and purified protein derivative (PPD) skin test prior to baseline to exclude patients with (latent) tuberculosis. Eligible patients were included into the study within 2 weeks after screening, and were seen at baseline, week 4 and week 12 .

Clinical assessment included a 68 joint count for tenderness and 66 joint count for swelling, a psoriasis area and severity index (PASI), a subject's visual analogue scale (VAS) score for pain, ranging from $0 \mathrm{~mm}$ (no pain) to $100 \mathrm{~mm}$ (the worst possible pain), a subject's and investigator's global disease assessment and a Health Assessment Questionnaire (HAQ) for functional (dis)ability. Furthermore, C-reactive protein (CRP) levels and erythrocyte sedimentation rate (ESR) were determined. A blinded, independent assessor performed the clinical evaluation. The 28-joint Disease Activity Score (DAS28), which has been shown to discriminate between active drug and placebo in clinical trials in PsA, was chosen to monitor changes in clinical disease activity after therapy. ${ }^{22}{ }^{23}$ In addition, the American College of Rheumatology (ACR) criteria for improvement were assessed. ${ }^{24}$

\section{Treatment}

Patients were randomised to receive subcutaneous injections with either adalimumab $40 \mathrm{mg}$ or matching placebo at baseline (day 1 ) and day 15 in a 1:1 ratio. After the second arthroscopy all patients received adalimumab $40 \mathrm{mg}$ every other week.

\section{Arthroscopy}

A needle arthroscopy of an actively inflamed joint (knee, ankle, or wrist) was performed under local anaesthesia in all patients before treatment and 28 days after initiation of study medication from the same joint. The procedures for needle arthroscopy and tissue processing were performed as described previously in detail. ${ }^{25}$ In summary, to minimise sampling error biopsies were taken from six or more sites of the joint during each procedure. $^{26}{ }^{27}$ ST biopsy specimens were immediately embedded in TissueTek OCT (Miles Diagnostics, Elkhart, Indiana, USA), snap frozen by immersion in methylbutane $\left(-80^{\circ} \mathrm{C}\right)$ and stored in liquid nitrogen until further processing Before staining, coded ST samples were cut with a cryostat $(5 \mu \mathrm{m})$, fixed with acetone and endogenous protease activity was blocked with $0.3 \%$ hydrogen peroxide.

\section{Immunohistochemical analysis}

Serial sections were stained with the following antibodies: antiCD3 (SK7; BD Biosciences, San Jose, California, USA), anti-CD4 (SK3; BD Biosciences), anti-CD8 (C8/114B; Dako, Glostrup, Denmark), anti-CD15 (C3D-1; Dako), anti-CD22 (CLB-B-ly/ 1,6B11; Sanquin, Amsterdam, The Netherlands), anti-CD38 (HB-7; BD Biosciences), anti-CD55 (clone 67; Serotech, Oxford, UK), anti-CD68 (EMB11; Dako) and anti-CD163 (5C6 FAT; Bachem Peninsula Laboratories, San Carlos, California, USA) to analyse the cell infiltrate. Antibodies against myeloid-related protein (MRP)8 (8-5C2; BMA Biomedicals, Augst, Switzerland) and MRP14 (S36.48; BMA Biomedicals) were used to detect infiltrating monocytes/macrophages in an early stage of differentiation.

For immunohistochemical analysis of cytokine expression, interleukin (IL)1 $\beta$ (2D8; Immunokontact, Stockholm, Sweden) and IL6 (B-E8; Invitrogen, Breda, The Netherlands) were stained. Furthermore, von Willebrand factor (vWF) (F8/86; Dako) was used as a marker to detect blood vessels. Additionally, the expression of matrix metalloproteinase (MMP)3 (MAB1339; Bio-Connect, Huissen, The Netherlands) and MMP13 (VIIIA2; Oncogene, Cambridge, Massachusetts, USA) was determined.

Sections with non-assessable tissue, defined by the absence of an intimal lining layer, were excluded from analysis. Staining for cellular markers was performed using a three-step immunoperoxidase method as previously described. ${ }^{28}$ For the determination of cytokine expression, biotinylated tyramine (BT) was used for amplification after incubation with the secondary antibody and incubation with streptavidin-horseradish peroxidase (HRP) conjugate was followed by detection with aminoethylcarbazole (AEC), as previously described. ${ }^{29}{ }^{30}$ For control sections, the primary antibodies were omitted or irrelevant antibodies were applied.

\section{Digital image analysis}

After immunohistochemical staining, all sections were coded and randomly analysed by computer-assisted digital image analysis (DIA). For all markers, 18 high-power fields were analysed. CD68 and CD163 expression (macrophage markers) were analysed separately in the intimal lining layer and the synovial sublining. The images of the high-power fields were analysed using the Owin analysis system (Leica, Cambridge, UK), as described in detail previously. ${ }^{31} 32$

\section{Statistical analysis}

SPSS for Windows (V 12.0.2; SPSS, Chicago, Illinois, USA) was used for statistical analysis. Baseline characteristics between the two groups were compared using a Student $t$ test for normal distributed data and a Mann-Whitney $U$ test for variables with a very skewed distribution. Correlations of changes in clinical parameters and immunohistochemical markers were analysed with Spearman rank correlation. Additionally, each of the end points was analysed using an analysis of covariance model (ANCOVA) after rank transformation to correct for baseline 
differences. ${ }^{33}$ The model included terms for treatment as a fixed effect and the baseline measurement as a covariate. The aim was to assess the treatment difference.

\section{RESULTS}

\section{Demographic features}

A total of 24 patients ( 15 men, 9 women) were included in the trial, 12 patients were randomised to receive adalimumab and 12 placebo treatment. The mean age was 42.8 (range 21-61) years for the patients in the adalimumab group and 47.2 (25-78) years in the placebo group (table 1). The mean PsA disease duration was comparable in both groups. Concomitant methotrexate was used by seven patients in the adalimumab group and five patients in the placebo group in a comparable dose (mean $18.2 \mathrm{mg} /$ week and $19.0 \mathrm{mg} /$ week, respectively). None of the patients had used tumour necrosis factor (TNF) inhibitors in the past. Most patients $(n=16)$ had polyarticular involvement according to the Moll and Wright classification, ${ }^{34}$ a minority had an oligoarticular phenotype $(n=7)$ or predominantly distal interphalangeal involvement $(n=1)$. Two of the patients with polyarticular disease also had axial involvement. The PsA phenotypes were not equally distributed between the 2 groups, with the placebo group harbouring more patients with polyarticular disease than the adalimumab group (10 versus $6)$. Despite this difference, the patient groups were comparable with regard to disease activity markers, such as CRP and DAS28.

All patients received the two injections with study medication according to the protocol. Overall study medication was well tolerated. No infections other than common cold were reported in the 4-week study period. One patient in the placebo group complained of more pain in her ankle after the first arthroscopy, but could undergo the second arthroscopy.

\section{Clinical response}

As anticipated, a markedly positive effect of adalimumab treatment was seen on the DAS28, ${ }^{23}$ which was 1.92 units lower compared with placebo after 4 weeks of treatment $(95 \%$ confidence interval (CI) 1.07 to $2.77, \mathrm{p}<0.001$ ) (fig 1 ). The mean

Table 1 Demographic and clinical features of the 24 patients with psoriatic arthritis (PsA) enrolled in the study

\begin{tabular}{lll}
\hline & Adalimumab (n= 12) & Placebo (n= 12) \\
\hline Age, years & $42.8(21-61)$ & $47.2(25-78)$ \\
No. men/women & $9 / 3$ & $6 / 6$ \\
No. (\%) currently receiving MTX & $7(58)$ & $5(42)$ \\
Dose MTX, mg/week & $18.2(10-25)$ & $19.0(15-25)$ \\
PsA disease duration, years & $5.5(0.4-14.1)$ & $8.4(1.9-18.2)$ \\
No. (\%) RF positive & $2(17)$ & $1(8)$ \\
No. (\%) anti-CCP positive & $1(8)$ & 0 \\
No. (\%) erosive & $7(58)$ & $5(42)$ \\
ESR, mm/h & $24.2(4-66)$ & $22.4(3-66)$ \\
CRP, mg/litre & $19.9(2.3-81.6)$ & $9.9(1.3-26.7)$ \\
DAS28 score & $4.67(3.0-5.78)$ & $5.07(2.21-6.83)$ \\
Patient global assessment of & $73(45-94)$ & $62.8(18-92)$ \\
disease activity (VAS 0- & & \\
100 mm) & & $67.4(11-89)$ \\
Patient assessment of pain (VAS & $72.8(55-91)$ & $4.72(0-7.0)$ \\
0-100 mm) & $5.89(0-14.0)$ & \\
PASI & &
\end{tabular}

All values are mean (range) except where indicated otherwise.

CRP, C-reactive protein; DAS28, 28-joint Disease Activity Score; ESR, erythrocyte sedimentation rate; MTX, methotrexate; PASI, psoriasis area and severity index; RF, rheumatoid factor; VAS, visual analogue scale.
(SD) DAS28 decreased from 4.67 (0.98) to 2.87 (1.27) 1 month after initiation of adalimumab therapy. This improvement was not seen in the placebo group, where the mean DAS28 was 5.07 (1.29) before versus 5.20 (1.31) after treatment. After 4 weeks of treatment, 11 of the adalimumab patients fulfilled the European League Against Rheumatism (EULAR) criteria for clinical response $^{23} 35$ (6 patients were good and 5 were moderate responders), versus 0 in the placebo group. Clinical improvement was sustained at week 12 , when all 12 adalimumabtreated patients fulfilled the EULAR criteria for clinical response (7 good and 5 moderate responders). Based on the 68 tender joint count and 66 swollen joint count an ACR20 response for improvement ${ }^{24}$ was observed in 5 patients after 4 weeks of adalimumab treatment (of which 4 also fulfilled the ACR50 response criteria), but in none of the placebo-treated patients. After 12 weeks of adalimumab treatment 10 patients fulfilled ACR20 criteria, of which 7 also met the ACR50 response criteria.

The mean PASI score after 4 weeks of adalimumab treatment was 2.61 points lower compared to placebo $(95 \% \mathrm{CI}-0.08$ to $5.30, p=0.056$ ). The mean PASI decreased from $5.89(4.25)$ to 4.01 (2.49) in the adalimumab group, whereas there was a slight increase in the placebo group from $4.72(2.55)$ to 5.45 (4.05).

At 4 weeks the ESR and CRP levels were respectively $58 \%$ (95\% CI $30 \%$ to $86 \%, p=0.001)$ and $57 \%(95 \%$ CI $29 \%$ to $84 \%$, $\mathrm{p}<0.001)$ lower after adalimumab treatment than after placebo treatment. The mean ESR was reduced from $24.2(21.7) \mathrm{mm} / \mathrm{h}$ to $8.1(7.5) \mathrm{mm} / \mathrm{h}$ after adalimumab treatment, and the mean CRP from 19.9 (25.7) $\mathrm{mg} /$ litre to 2.1 (1.4) $\mathrm{mg} /$ litre, whereas after placebo treatment there was no clear cut change: ESR from 22.4 (18.7) to $19.6(11.9) \mathrm{mm} / \mathrm{h}$ and CRP from 9.9 (9.1) to 9.2 (10.0) $\mathrm{mg} /$ litre, respectively.

\section{Immunohistochemical analysis}

Paired pretreatment and post-treatment synovial samples from 19 patients were available for analysis. The pretreatment ST biopsies of three patients did not contain an intimal lining layer and therefore did not pass the quality control tests. Due to an unfortunate freezer accident ST biopsies of two other patients were lost. The remaining 19 paired ST samples were analysed, 10 were in the adalimumab group and 9 in the placebo group. The results of this analysis are shown in table 2 .

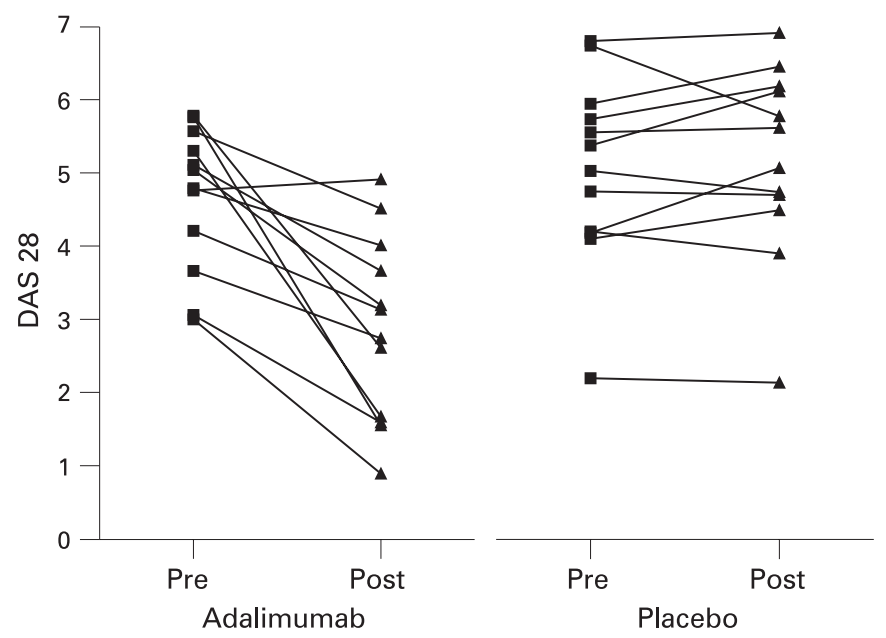

Figure 1 Effect of treatment with either adalimumab or placebo on the individual 28-joint Disease Activity Score (DAS28). A marked reduction is seen after adalimumab treatment for 4 weeks. 
Table 2 Median values (standard error (SE) of the median) for the synovial biomarkers before treatment and median reduction (SE of the median) after 4 weeks of treatment in each group and $p$ value of the ranked analysis of covariance (ANCOVA) applied

\begin{tabular}{|c|c|c|c|c|c|}
\hline & \multicolumn{2}{|l|}{ Adalimumab } & \multicolumn{2}{|l|}{ Placebo } & \multirow{2}{*}{$\begin{array}{l}\text { ANCOVA } \\
\text { p Value }\end{array}$} \\
\hline & Before & Reduction & Before & Reduction & \\
\hline CD68 total & 1927 (133) & 435 (197) & $835(516)$ & $-534(567)$ & 0.31 \\
\hline CD68L & $378(28)$ & $236(61)$ & 177 (140) & $-419(249)$ & 0.35 \\
\hline CD68SL & $1423(262)$ & $147(59)$ & 753 (628) & -184 (99) & 0.23 \\
\hline CD163 total & $1243(208)$ & 765 (309) & 480 (178) & 286 (409) & 0.67 \\
\hline CD163L & $426(203)$ & $167(72)$ & $68(8)$ & $39(46)$ & 0.15 \\
\hline CD163SL & $1081(155)$ & $674(265)$ & $468(206)$ & 256 (389) & 0.85 \\
\hline CD4 & $1130(265)$ & $386(278)$ & $184(21)$ & $-148(589)$ & 0.084 \\
\hline CD8 & 177 (103) & $103(72)$ & $27(7)$ & $-4(7)$ & 0.12 \\
\hline CD15 & $35(13)$ & $22(8)$ & $13(1)$ & $12(28)$ & 0.42 \\
\hline CD22 & 306 (167) & $210(145)$ & $44(7)$ & $20(27)$ & 0.89 \\
\hline CD38 & $15(11)$ & $4(1)$ & $4(1)$ & $1(1)$ & 0.83 \\
\hline CD55 & $660(218)$ & $85(145)$ & $681(30)$ & $230(288)$ & 0.60 \\
\hline MRP14 & $3976(1380)$ & 2814 (2339) & $1837(1360)$ & 489 (247) & 0.82 \\
\hline MMP3 & 247021 (101 010) & 138679 (99 428) & 17680 (1913) & 138 (529) & 0.64 \\
\hline MMP13 & 25822 (15 822) & $9188(8653)$ & $14673(10350)$ & $-9002(5469)$ & $0.033^{*}$ \\
\hline
\end{tabular}

CD68+ macrophages (total), CD68+ macrophages in the intimal lining layer (L) and in the synovial sublining (SL), CD163+ cells (subset of macrophages) (total), CD163+ cells in L and SL, CD3+ T cells, CD4+ and CD8+ T cells, CD15+ neutrophils, CD22 + B cells, CD38+ plasma cells and CD55+ fibroblast-like synoviocytes are provided as cells/mm². Expression of von Willebrand Factor (vWF), interleukin (IL)1 $\beta$, IL6, myeloid related protein (MRP)8, MRP14, matrix metalloproteinase (MMP)3, MMP13, are provided as median (SE of the median) integrated optical density (IOD)/mm². Differences before treatment between the groups were statistically significant for CD163+ cells (total, L and SL), CD8+ cells and MMP3 expression, which were higher in the adalimumab group. After ANCOVA was applied to correct for baseline imbalances, the effect of treatment after 4 weeks was significant only for the reduction in the number of CD3-positive cells $(p=0.035)$ and MMP13 expression $(=0.033)^{*}$.

Despite randomisation, there were clear differences at baseline for several synovial markers between adalimumab and placebo groups, as shown in table 2 (adalimumab and placebo before). Most of these baseline differences were not statistically significant except for the number of CD8-positive cells, CD163positive cells and MMP3 expression, which were significantly higher in the adalimumab group. A marked reduction was observed in most cell types after active treatment. The effect after adalimumab was significant for CD3-positive T cells: there was a median decrease of 248 cells $/ \mathrm{mm}^{2}$ after adalimumab compared to placebo treatment. There was clear interindividual variability, which is a well known phenomenon in patients with various arthritides including PsA. ${ }^{46}$ However, on the group level there was a marked decrease in CD3-positive $\mathrm{T}$ cells (median (standard error (SE)) of the median: 212 (230) cells/ $\mathrm{mm}^{2}$ ) in the adalimumab group (fig 2), whereas in the placebo group there was an increase $\left(36(33)\right.$ cells $\left./ \mathrm{mm}^{2}\right)$. A similar effect was observed for the two $\mathrm{T}$ cell subpopulations: there was a trend towards a reduction of CD4-positive cells (386 (278) cells/ $\mathrm{mm}^{2}$ ) after adalimumab compared to an increase (148 (589) cells $/ \mathrm{mm}^{2}$ ) after placebo treatment; and a reduction of CD8positive cells $\left(103(72)\right.$ cells $/ \mathrm{mm}^{2}$ ) after adalimumab versus a small increase (4 (7) cells $/ \mathrm{mm}^{2}$ ) after placebo treatment.

Following adalimumab treatment there was also a decrease in the number of CD163-positive cells (resident macrophages) and CD68-positive macrophages, especially in the synovial sublining, but these changes did not reach statistical significance, possibly due to the relatively small number of patients. Similar changes were observed for MRP8 and MRP14-positive macrophages (infiltrating monocytes/macrophages in an early stage of differentiation). There were also trends towards decreased infiltration by CD22-positive B cells, CD38-positive plasma cells and CD15-positive neutrophils after active treatment.
There was a trend towards reduction in the expression of the vascular marker vWF and the proinflammatory cytokines IL1 and IL6 after treatment with adalimumab as compared to placebo, but the differences were not statistically significant. There was considerable reduction of expression of MMP3 and MMP13 in the adalimumab group as compared to placebo. The expression of MMP13 was decreased with 9188 (8653) IOD/ $\mathrm{mm}^{2}$ (median (SE)) after adalimumab treatment as compared to an increase of 9002 (5469) IOD $/ \mathrm{mm}^{2}$ after placebo. When ANCOVA was applied to correct for the imbalances at baseline, it turned out that the baseline measurement had the strongest effect on change in any parameter tested, but for reduction in the number of CD3-positive cells and MMP13 expression the effect of treatment remained significant ( $p=0.035$ for CD3positive cells and $p=0.033$ for expression of MMP13).

\section{Correlation between clinical improvement and changes in synovial biomarkers}

For the cellular markers clinical improvement was strongly correlated with a decrease in CD3-positive T cells (Spearman rho $=0.644, \quad p=0.003), \quad$ CD4-positive cells $\quad(r h o=0.649$, $\mathrm{p}=0.003$ ) and MRP8-positive macrophages (rho $=0.561$, $\mathrm{p}=0.012$ ) (fig 3), but there was no statistically significant correlation with changes in other cell types. There was also a strong correlation between clinical improvement and the reduction of $\mathrm{MMP13}$ (rho $=0.619, \mathrm{p}=0.005$ ) (fig 3) and MMP3 (rho $=0.560, p=0.013$ ).

\section{DISCUSSION}

This placebo-controlled study with adalimumab was conducted to address the question which features in PsA ST samples could be used as a biomarker for clinical efficacy on the group level in relatively small studies of short duration. The results presented 
Figure 2 Representative photograph showing CD3+ T cells (red-brown) in psoriatic arthritis synovial tissue before and after treatment with adalimumab (upper panel left and right) or placebo (lower panel left and right). Magnification $\times 200$. A marked reduction of the number of $\mathrm{CD} 3+\mathrm{T}$ cells was observed after 4 weeks of adalimumab treatment.
Figure 3 Scatter plots showing individual data points for the correlation between change in 28-joint Disease Activity Score ( $\triangle \mathrm{DAS} 28$, a positive value represents clinical improvement) on the $y$ axis and change in biomarker (a positive value represents a reduction of the expression) on the $x$ axis after 4 weeks for CD3-positive cells (rho $=0.644$, $\mathrm{p}=0.003)$, CD4-positive cells (rho $=0.649, p=0.003$ ), expression of myeloid-related protein (MRP)8 $($ rho $=561, p=0.012)$ and matrix metalloproteinase (MMP)13 (rho $=619$, $\mathrm{p}=0.005)$.
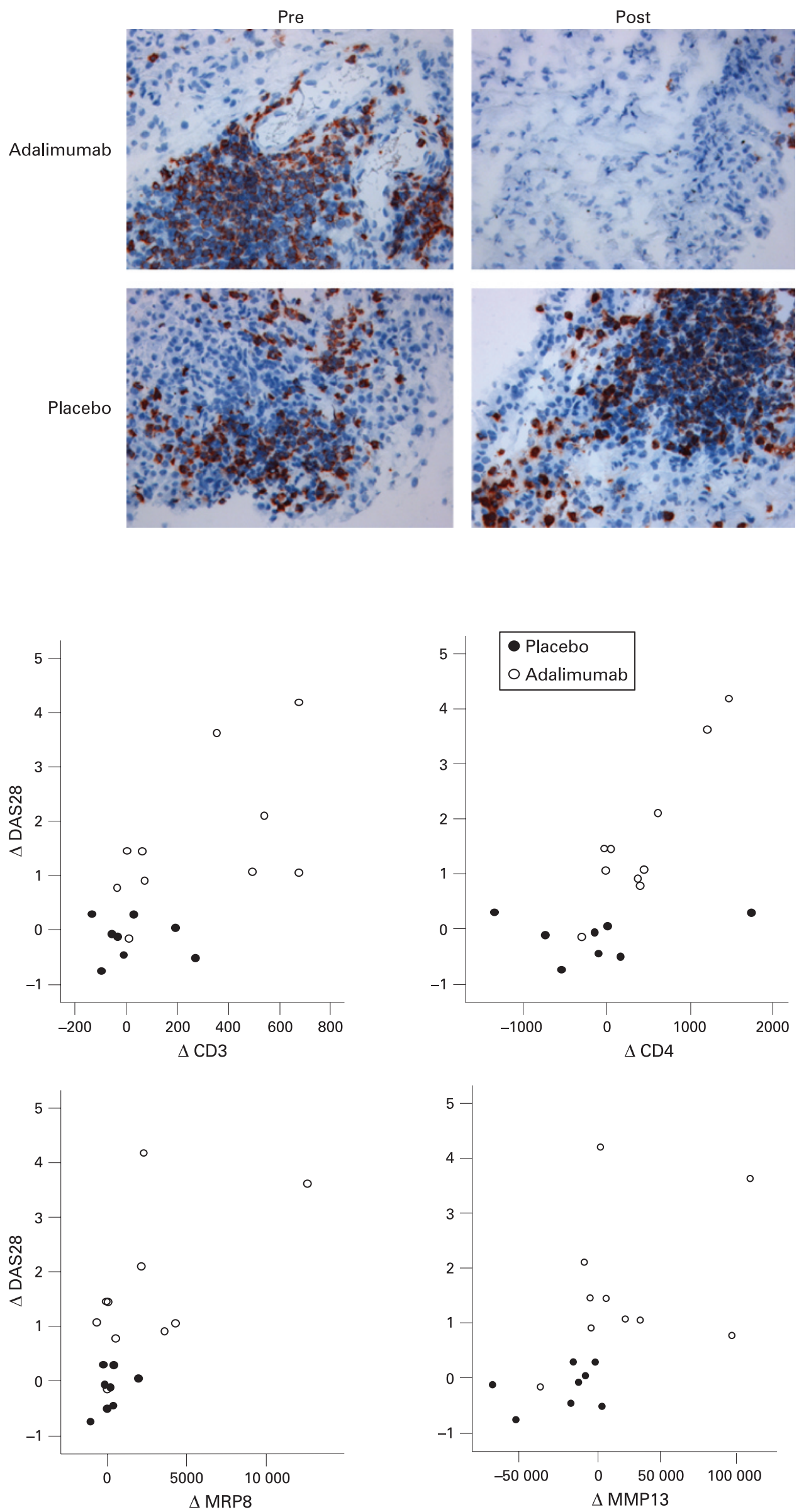
here show that clinically effective adalimumab therapy is particularly associated with a marked reduction in CD3-positive $T$ cell infiltration and expression of MMP13 in the ST of patients with PsA 4 weeks after initiation of treatment.

Previous work on synovial biomarkers in patients with PsA has been mainly limited to open studies, mostly of longer duration. Open label treatment of 10 patients with PsA with methotrexate resulted in a decrease in $T$ cells and macrophages as well as reduced expression of IL8, E-selectin, intercellular adhesion molecule 1 (ICAM-1) and MMP3 after 6 to 12 months of treatment. ${ }^{14}$ In another study 52 patients with peripheral arthritis due to spondyloarthritis were included; 16 of these had PsA. ${ }^{15}$ The patients underwent synovial biopsy at baseline and 12 weeks following different treatment regimens (infliximab, etanercept, sulfasalazine or no DMARD). Clinical improvement correlated with a decrease in CD163-positive macrophages, polymorphonuclear cells (PMNs) and MMP3 expression. A study on the effects of TNF blockade showed in 11 patients with PsA, who were treated with infliximab $(3 \mathrm{mg} / \mathrm{kg})$ combined with stable methotrexate treatment, a significant reduction of ICAM-1, vWF and $\alpha \mathrm{v} \beta 3$ expression. ${ }^{17}$ There was also a trend towards a reduction of $\mathrm{T}$ cells and macrophages. Similarly, another study demonstrated a decrease in macrophage numbers and vascular markers in the synovium of nine patients with PsA 8 weeks after initiation of infliximab $(5 \mathrm{mg} / \mathrm{kg}$ ) treatment. ${ }^{18} \mathrm{~A}$ study on the effects of alefacept revealed a significant decrease in $T$ cell numbers after 4 weeks of treatment, and a significant reduction of $\mathrm{T}$ cells and macrophages after 12 weeks of treatment in 11 patients with PsA. ${ }^{6}$ Finally, experimental treatment with IL10 subcutaneously for 4 weeks resulted in decreased $\mathrm{T}$ cell and macrophage infiltration in the synovium. ${ }^{37}$

The present study was designed to determine which synovial biomarkers are associated on the group level with active treatment, identical to the approach that we have previously described in patients with RA. ${ }^{8}$ In RA macrophage numbers were previously identified as synovial biomarkers associated with active treatment. These results have been confirmed and validated in various studies. ${ }^{9} 1038$ Of interest, although we did observe clear trends towards decreased numbers of macrophages and macrophage subsets after active treatment, analysis of covariance indicates that in PsA especially the number of CD3positive $\mathrm{T}$ cells and the expression of MMP13 could be used to screen for potentially active drugs in small proof of concept studies of short duration. The results presented here underscore the important role of $\mathrm{T}$ cells in the pathogenesis of PsA, ${ }^{39}$ consistent with the observation that specific targeting of $T$ cells may result in clinical benefit in this disease. ${ }^{640}$

A potential drawback of this study is the fact that there were baseline differences-in clinical and synovial variablesbetween the adalimumab and placebo group despite randomisation, which is probably related to the relatively small number of patients. The ANCOVA model, however, includes the baseline value for each marker as a covariate, thereby correcting for these baseline imbalances. ${ }^{41}$ Using this model to describe the relationship between clinical improvement and changes in ST, the effect of treatment was sustained for a reduction of $\mathrm{T}$ cells and MMP13 expression. Another potential limitation of this exploratory study is related to the high number of synovial parameters tested and the chance of erroneously reporting statistical significance in the context of multiple comparisons. The limited power of our study did not allow a conservative Bonferroni correction. Of importance, other investigators have very recently independently confirmed the specific decrease in
CD3+ T cells in the synovium after initiation of TNF blockade in patients with PsA. ${ }^{42}$ Thus, it appears unlikely that the identification of CD3+ $\mathrm{T}$ cells as a key synovial biomarker associated with active treatment can merely be explained by chance.

The reduction of synovial inflammation associated with clinical improvement of the joint and skin after adalimumab treatment is also consistent with previous reports showing a decrease in leukocyte numbers (including $\mathrm{T}$ cells and macrophages), as well as reduced vascularity and expression of proinflammatory cytokines and MMPs in the synovium of patients with PsA after infliximab treatment. ${ }^{15-18}$ The cellular changes might be explained in part by changes in cell migration due to reduced neoangiogenesis and reduced expression of adhesion molecules and chemokines, as suggested previously. $^{14} 161743$

Analysis of molecular markers in synovial tissue is increasingly used in clinical trials on targeted therapies. With this approach, tissue specificity is not a problem and examination of serial biopsy samples can be used to monitor the response in individual patients and screen for interesting biological effects at the site of inflammation. This study clearly shows that changes in $\mathrm{T}$ cell numbers and the expression of $\mathrm{MMP13}$ in the synovium of patients with PsA may be used as biomarkers to screen for effective therapies during early drug development. It can be anticipated that future developments will include the use of more extensive markers of synovial inflammation and joint degradation as well as the use of panels of biomarkers in serum and synovial tissue samples.

Acknowledgements: The authors wish to thank llse Burgman, Marjolein Vinkenoog and $\mathrm{Dr}$ Tom Smeets for their expert assistance with immunohistochemistry and digital image analysis.

Funding: This clinical study was supported by Abbott BV, The Netherlands. DMG was supported by the Dutch Arthritis Association ("Reumafonds"). This research was also supported by the European Community's FP6 funding ("Autocure").

Competing interests: This publication reflects only the author's views; the European Community is not liable for any use that may be made of the information herein. This research is integrated in the work of the OMERACT Special Interest Group on Synovial Analysis in Clinical Trials

Ethics approval: The study protocol was approved by the medical ethics committee of the institute and all patients signed informed consent before start of the study.

\section{REFERENCES}

1. Kraan MC, Haringman JJ, Post WJ, Versendaal J, Breedveld FC, Tak PP. Immunohistological analysis of synovial tissue for differential diagnosis in early arthritis. Rheumatology (Oxford) 1999;38:1074-80.

2. Baeten D, Steenbakkers PG, Rijnders AM, Boots AM, Veys EM, De Keyser F. Detection of major histocompatibility complex/human cartilage gp-39 complexes in rheumatoid arthritis synovitis as a specific and independent histologic marker. Arthritis Rheum 2004;50:444-51.

3. Tak PP, Bresnihan B. The pathogenesis and prevention of joint damage in rheumatoid arthritis: advances from synovial biopsy and tissue analysis. Arthritis Rheum 2000;43:2619-33.

4. van Kuijk AW, Reinders-Blankert P, Smeets TJ, Dijkmans BA, Tak PP. Detailed analysis of the cell infiltrate and the expression of mediators of synovial inflammation and joint destruction in the synovium of patients with psoriatic arthritis: implications for treatment. Ann Rheum Dis 2006;65:1551-7.

5. Tak PP. Lessons learnt from the synovial tissue response to anti-rheumatic treatment. Rheumatology (Oxford) 2000;39:817-20.

6. Kraan MC, van Kuijk AW, Dinant HJ, Goedkoop AY, Smeets TJ, de Rie MA, et al. Alefacept treatment in psoriatic arthritis: reduction of the effector T cell population in peripheral blood and synovial tissue is associated with improvement of clinical signs of arthritis. Arthritis Rheum 2002;46:2776-84.

7. Gerlag DM, Tak PP. Novel approaches for the treatment of rheumatoid arthritis: lessons from the evaluation of synovial biomarkers in clinical trials. Best Pract Res Clin Rheumatol 2008;22:311-23.

8. Gerlag DM, Haringman JJ, Smeets TJ, Zwinderman AH, Kraan MC, Laud PJ, et al. Effects of oral prednisolone on biomarkers in synovial tissue and clinical improvement in rheumatoid arthritis. Arthritis Rheum 2004;50:3783-91. 
9. Wijbrandts CA, Vergunst CE, Haringman JJ, Gerlag DM, Smeets TJ, Tak PP. Absence of changes in the number of synovial sublining macrophages after ineffective treatment for rheumatoid arthritis: implications for use of synovial sublining macrophages as a biomarker. Arthritis Rheum 2007:56:3869-71.

10. Haringman JJ, Gerlag DM, Zwinderman AH, Smeets TJ, Kraan MC, Baeten D, et al. Synovial tissue macrophages: a sensitive biomarker for response to treatment in patients with rheumatoid arthritis. Ann Rheum Dis 2005;64:834-8.

11. Smeets TJ, Kraan MC, Versendaal J, Breedveld FC, Tak PP. Analysis of serial synovial biopsies in patients with rheumatoid arthritis: description of a control group without clinical improvement after treatment with interleukin 10 or placebo. $J$ Rheumatol 1999;26:2089-93.

12. Baeten D, Houbiers J, Kruithof E, Vandooren B, Van Den BF, Boots AM, et al. Synovial inflammation does not change in the absence of effective treatment: implications for the use of synovial histopathology as biomarker in early phase clinical trials in rheumatoid arthritis. Ann Rheum Dis 2006:65:990-7.

13. Cunnane G, Madigan A, Murphy E, Fitzgerald O, Bresnihan B. The effects of treatment with interleukin-1 receptor antagonist on the inflamed synovial membrane in rheumatoid arthritis. Rheumatology (Oxford) 2001;40:62-9.

14. Kane D, Gogarty M, O'Leary J, Silva I, Bermingham N, Bresnihan B, et al. Reduction of synovial sublining layer inflammation and proinflammatory cytokine expression in psoriatic arthritis treated with methotrexate. Arthritis Rheum 2004;50:3286-95.

15. Kruithof E, De RL, Vandooren B, De KF, Fitzgerald O, Mclnnes I, et al. Identification of synovial biomarkers of response to experimental treatment in early-phase clinical trials in spondylarthritis. Arthritis Rheum 2006;54:1795-804.

16. Goedkoop AY, Kraan MC, Teunissen MB, Picavet DI, de Rie MA, Bos JD, et al. Early effects of tumour necrosis factor alpha blockade on skin and synovial tissue in patients with active psoriasis and psoriatic arthritis. Ann Rheum Dis 2004;63:769-73.

17. Goedkoop AY, Kraan MC, Picavet DI, de Rie MA, Teunissen MB, Bos JD, et al. Deactivation of endothelium and reduction in angiogenesis in psoriatic skin and synovium by low dose infliximab therapy in combination with stable methotrexate therapy: a prospective single-centre study. Arthritis Res Ther 2004;6:R326-34.

18. Canete JD, Pablos JL, Sanmarti R, Mallofre C, Marsal S, Maymo J, et al. Antiangiogenic effects of anti-tumor necrosis factor alpha therapy with infliximab in psoriatic arthritis. Arthritis Rheum 2004:50:1636-41.

19. Mease PJ, Gladman DD, Ritchlin CT, Ruderman EM, Steinfeld SD, Choy EH, et al. Adalimumab for the treatment of patients with moderately to severely active psoriatic arthritis: results of a double-blind, randomized, placebo-controlled trial. Arthritis Rheum 2005;52:3279-89.

20. Taylor W, Gladman D, Helliwell P, Marchesoni A, Mease P, Mielants H. Classification criteria for psoriatic arthritis: development of new criteria from a large international study. Arthritis Rheum 2006:54:2665-73.

21. Chandran V, Schentag CT, Gladman DD. Sensitivity of the classification of psoriatic arthritis criteria in early psoriatic arthritis. Arthritis Rheum 2007:57:1560-3.

22. Prevoo ML, van't Hof MA, Kuper HH, van Leeuwen MA, van de Putte LB, van Riel PL. Modified disease activity scores that include twenty-eight-joint counts. Development and validation in a prospective longitudinal study of patients with rheumatoid arthritis. Arthritis Rheum 1995;38:44-8.

23. Fransen J, Antoni C, Mease PJ, Uter W, Kavanaugh A, Kalden JR, et al. Performance of response criteria for assessing peripheral arthritis in patients with psoriatic arthritis: analysis of data from randomised controlled trials of two tumour necrosis factor inhibitors. Ann Rheum Dis 2006;65:1373-8.

24. Felson DT, Anderson JJ, Boers M, Bombardier C, Furst D, Goldsmith C, et al. American College of Rheumatology. Preliminary definition of improvement in rheumatoid arthritis. Arthritis Rheum 1995;38:727-35.

25. Kraan MC, Reece RJ, Smeets TJ, Veale DJ, Emery P, Tak PP. Comparison of synovial tissues from the knee joints and the small joints of rheumatoid arthritis patients: implications for pathogenesis and evaluation of treatment. Arthritis Rheum 2002; 46:2034-8
26. Dolhain RJ, Ter Haar NT, De Kuiper R, Nieuwenhuis IG, Zwinderman AH, Breedveld $\mathrm{FC}$, et al. Distribution of $\mathrm{T}$ cells and signs of T-cell activation in the rheumatoid joint: implications for semiquantitative comparative histology. $\mathrm{Br} J$ Rheumatol 1998:37:324-30.

27. Boyle DL, Rosengren S, Bugbee W, Kavanaugh A, Firestein GS. Quantitative biomarker analysis of synovial gene expression by real-time PCR. Arthritis Res Ther 2003;5:R352-60

28. Tak PP, van der Lubbe PA, Cauli A, Daha MR, Smeets TJ, Kluin PM, et al. Reduction of synovial inflammation after anti-CD4 monoclonal antibody treatment in early rheumatoid arthritis. Arthritis Rheum 1995;38:1457-65.

29. Smeets TJ, Kraan MC, Galjaard S, Youssef PP, Smith MD, Tak PP. Analysis of the cell infiltrate and expression of matrix metalloproteinases and granzyme $B$ in paired synovial biopsy specimens from the cartilage-pannus junction in patients with RA. Ann Rheum Dis 2001;60:561-5.

30. Smeets TJ, Barg EC, Kraan MC, Smith MD, Breedveld FC, Tak PP. Analysis of the cell infiltrate and expression of proinflammatory cytokines and matrix metalloproteinases in arthroscopic synovial biopsies: comparison with synovial samples from patients with end stage, destructive rheumatoid arthritis. Ann Rheum Dis 2003:62:635-8.

31. Kraan MC, Smith MD, Weedon H, Ahern MJ, Breedveld FC, Tak PP. Measurement of cytokine and adhesion molecule expression in synovial tissue by digital image analysis. Ann Rheum Dis 2001;60:296-8.

32. Haringman JJ, Vinkenoog M, Gerlag DM, Smeets TJ, Zwinderman AH, Tak PP. Reliability of computerized image analysis for the evaluation of serial synovial biopsies in randomized controlled trials in rheumatoid arthritis. Arthritis Res Ther 2005; 7:R862-7.

33. Conover WJ, Iman RL. Analysis of covariance using the rank transformation. Biometrics 1982;38:715-24.

34. Moll JM, Wright V. Psoriatic arthritis. Semin Arthritis Rheum 1973;3:55-78

35. van Gestel AM, Prevoo ML, van't Hof MA, van Rijswijk MH, van de Putte LB, van Riel PL. Development and validation of the European League Against Rheumatism response criteria for rheumatoid arthritis. Comparison with the preliminary American College of Rheumatology and the World Health Organization/International League Against Rheumatism Criteria. Arthritis Rheum 1996;39:34-40.

36. Tak PP, Smeets TJ, Daha MR, Kluin PM, Meijers KA, Brand R, et al. Analysis of the synovial cell infiltrate in early rheumatoid synovial tissue in relation to local disease activity. Arthritis Rheum 1997;40:217-25.

37. McInnes IB, Illei GG, Danning CL, Yarboro CH, Crane M, Kuroiwa T, et al. IL-10 improves skin disease and modulates endothelial activation and leukocyte effector function in patients with psoriatic arthritis. J Immunol 2001;167:4075-82.

38. Bresnihan B, Gerlag DM, Rooney T, Smeets TJ, Wijbrandts CA, Boyle D, et al. Synovial macrophages as a biomarker of response to therapeutic intervention in rheumatoid arthritis: standardization and consistency across centers. J Rheumatol 2007; 34:620-2.

39. Choy E. T cells in psoriatic arthritis. Curr Rheumatol Rep 2007:9:437-41.

40. Mease PJ, Gladman DD, Keystone EC. Alefacept in combination with methotrexate for the treatment of psoriatic arthritis: results of a randomized, double-blind, placebocontrolled study. Arthritis Rheum 2006;54:1638-45.

41. Vickers AJ, Altman DG. Statistics notes: analysing controlled trials with baseline and follow up measurements. BMJ 2001:323:1123-4.

42. Pontifex EK, Gogarty M, Gibbs A, Fearon U, Veale DJ, Bresnihan B, et al. Change in CD3 positive cell infiltration in psoriatic arthritis (PsA) synovial tissue correlates with change in DAS28 following initiation of biologic therapy. Ann Rheum Dis 2008;67(Suppl II):628.

43. Tracey D, Klareskog L, Sasso EH, Salfeld JG, Tak PP. Tumor necrosis factor antagonist mechanisms of action: A comprehensive review. Pharmacol Ther 2008:117:244-79. 